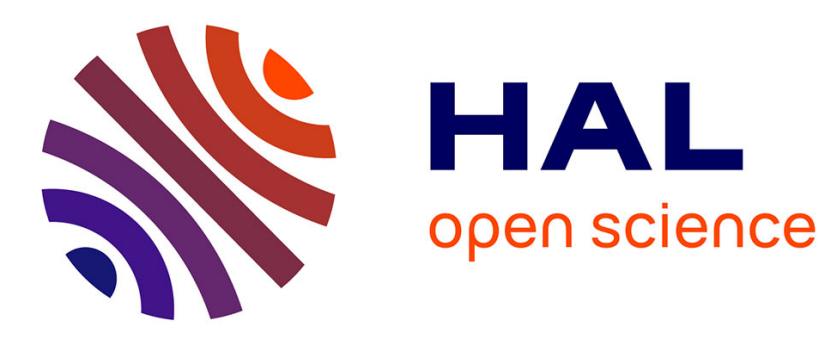

\title{
Dancing in the dark: Making sense of managerial roles during strategic conversations
}

Florence Allard-Poesi

\section{To cite this version:}

Florence Allard-Poesi. Dancing in the dark: Making sense of managerial roles during strategic conversations. Scandinavian Journal of Management, 2015, 31, pp.338 - 350. hal-01490734

\section{HAL Id: hal-01490734 \\ https://hal.science/hal-01490734}

Submitted on 23 Mar 2017

HAL is a multi-disciplinary open access archive for the deposit and dissemination of scientific research documents, whether they are published or not. The documents may come from teaching and research institutions in France or abroad, or from public or private research centers.
L'archive ouverte pluridisciplinaire HAL, est destinée au dépôt et à la diffusion de documents scientifiques de niveau recherche, publiés ou non, émanant des établissements d'enseignement et de recherche français ou étrangers, des laboratoires publics ou privés. 


\title{
Dancing in the Dark:
}

\section{Making Sense of Managerial Roles during Strategic Conversations}

\author{
Florence Allard-Poesi \\ Université Paris-Est \\ IRG (EA 2354) \\ France \\ allard-poesi@u-pec.fr
}

Scandinavian Journal of Management, vol. 31, n³, pp. 338-340.

\begin{abstract}
This article explores how managers make sense of their strategic roles when confronted with contradictory expectations from top management. Relying discourse analysis (DA), we analyze extracts of conversations between a director and a team of managers as they strive to elaborate a strategic project for a large association within the social sector. Our research complements prior research on managerial roles in showing that the sensemaking of managerial roles relies on the construction and contestation of scripted descriptions of the organization and its environment; 2 / demonstrating how the managers and the director both contribute to the fabric of contradicted versions of the managerial roles and 3/ how participants' will to power contribute to the "dance" observed.
\end{abstract}

Keywords: sensemaking; strategic conversation; managerial roles; contradictions; discourse

\section{Highlights}

- $\quad$ Analyze how managers make sense of their strategic roles during conversation.

- $\quad$ Detail the organization of two extracts of conversation.

- $\quad$ Demonstrate how managers construct contradictory conceptions of their roles.

- Show how the construction and contestation of roles rely on scripted descriptions.

- $\quad$ Point out that participants' will to power contributes to the oscillation among versions of role. 


\section{Introduction}

This article aims to understand how managers make sense of their strategic roles during conversations. Research in strategic management has emphasized the key role that middle managers play, particularly in terms of strategic renewal. Middle managers need to make sense of the strategic orientations given by top management, that is to interpret and enact these orientations through the creation of the adequate structures, systems and personnel. They also have to make sense of experiences and information from the field and possibly champion these strategic orientations (Mantere, 2005; Regnér, 2003). These contributions of middle managers to strategizing, which may be referred to as their strategic role, depend on their understanding of who they are in the organization and what is expected of them, i. e. on how they make sense of these strategic roles.

Following an interactionist perspective, a role may be defined as an "intermediary translation device between oneself and others" (Simpson \& Caroll, 2008, p. 33-34) of how one should act in a particular situation. Roles are intermediaries between personal identity (i.e. the more or less temporary stabilization of one's own definition of "who I am", Alvesson \& Willmott, 2002) and others, be they specific persons (i.e. the boss, some colleagues) or more generalized others ${ }^{1}$ including professional or occupational identities (i.e. the more or less temporary stabilization of some abstract and institutionalized conception of one's own profession).

This definition calls attention to the discursive and political dimensions of managers' roles. Roles, write Simpson and Carroll (2008, p. 33), "sit as boundary object[s] in the middle of intersubjective interactions" and "translate[s] meanings backwards and forwards between actors (p. 34)". They are the object of continuous negotiation between individual strivings and

\footnotetext{
${ }^{1}$ While managers' contribution to strategizing can be regarded as part of their occupation as managers, we prefer to talk about the manager's strategic role (and of managers' roles) rather than managers' occupations, considering that being a manager conveys a much more ambiguous, unstable and contextual definition compared to what is usually referred to as an occupation (e.g. doctor, firefighter..., see Bechky, 2006; 2011).
} 
external prescriptions, personal conceptions and organizational or institutional discourses (Mantere \& Vaara, 2008). As such, roles are the locus of power struggles and the dynamics of control and resistance (see Laine \& Vaara, 2007; Thomas, Sargent \& Hardy, 2011), where power, following a conversation analytic view of a Foucauldian conception (Foucault, 1982), is understood as relational and exercised in talk-in-interactions (Samra-Fredericks, 2005, p. 811; Heritage, 1987). In this perspective, the sensemaking of roles in organizations does not rely exclusively on the actions (i.e. the decision taken, the communicative practices) of those who are in a superior hierarchical position, but depends on both the superior's and the subordinates' communicative actions (Schneider, 2007) through which they “create, assemble, produce and reproduce the social structure through which they orient" (Heritage, 1987, p. 231).

While the managers' identity construction processes has received much attention in the last decade (see Alvesson \& Willmott, 2002; Alvesson, Ashcraft, \& Thomas, 2008; Ybema, Keenoy, Oswick, Bevereungen, Ellis, \& Sabelis, 2009), and while recent strategy-as-practice research has contributed to the understanding of manager roles in the sensemaking and enactment of strategy (see Rouleau, 2005; Balogun \& Johnson, 2004; Mantere, 2005; 2008), the actual construction of the managers' strategic role has been neglected.

We consider this problematic in so far that while managers are the maître d'oeuvre ${ }^{2}$ of strategy, they often face ambiguous if not contradictory expectations from top managers (Lüscher \& Lewis, 2008; Alvesson \& Sveningsson, 2003). As "Who we think we are (identity) as organizational actors shapes what we enact and how we interpret" (Weick, Sutcliffe \& Obstfeld,

\footnotetext{
${ }^{2}$ The maitre d'oeuvre, literally the "Master of Works", acts as a bridge, for example, between the architect and the end client and building companies.
} 
2005, p. 416), managers may be incapable of making sense of the strategic orientations and how to act, if they do not know what role they have in the strategic process and in the organization (see Balogun \& Johnson, 2004). Lack of clarity of participants' roles in a strategic project may also encourage useless struggles for territory, thereby impeding structuring and collective sensemaking (see Pattriotta \& Spedale, 2009; 2011).

In a similar way, managers may find it difficult to commit themselves to any one course of action (Maitlis \& Sonenshein, 2010) and so retrench themselves in a passive or cynical attitude regarding the top management's strategic initiatives (McCabe, 2009; Mantere \& Vaara, 2008).

This article aims to understand how managers make sense of their strategic roles when confronted with contradictory expectations from top management. Considering conversations and interactions as the privileged medium through which people negotiate and make sense of their roles (Balogun \& Johnson, 2004, p. 545), we rely here on Edwards and Potter (1992)'s version of Discourse Analysis, a variant of Conversational Analysis, to analyze conversations between a director and a team of managers who are in the process of elaborating a strategic project in a large French association within the social sector.

Our research contributes to prior research on managerial roles in three related ways. First, it shows that managers and the director make sense of the managers' strategic role by relying on descriptions of oneself and others (e.g. Simpson \& Carroll, 2008; Edwards, 1994; 1995), and on the construction and contestation of scripted descriptions of the organization and its environment. Second, while previous research has underscored that different organizational actors may hold different discourses about their roles in the strategy process (Mantere \& Vaara, 2008; Laine \& Vaara, 2007), our research shows how the same actors may develop, and 
oscillate, between different and contradictory conceptions of their roles during the same meeting; thereby engaging in a sort of dance that contributes to the lack of clarity (the dark) in the definition of the managers' role. Third, while prior research has shown that power struggles during conversations may lead to trench warfare between actors and the loss of sensemaking of the task at hand (Pattriotta \& Spedale, 2009), our analysis show how participants may also oscillate among contradictory concepts of their roles as the result of their will to power during the conversation, leading them to lose control over their argumentation. On the whole, the research shows how sensemaking of managerial roles evolves in, and is shaped by, discrete conversations between top management and middle managers in strategy meetings. It contributes to the understanding of how political and interpretative dynamics drive the sensemaking of managers' strategic roles in the organization during conversations among the actors.

This article is organized around four sections. First, we briefly review previous work on how managers make sense of their strategic roles. Second, we describe the context within which this research took place, and, the methods of data collection and analysis that were used. We then present the discourses of the director and the managers concerning the strategic roles of the managers, and conduct a detailed analysis of two sequences of conversations in which the managers and the director oscillate between different conceptions of their roles. Finally, we discuss the research contributions.

\section{Making Sense of Manager's Strategic Roles}

Three complementary strands of research may contribute to our understanding of how managers make sense of their strategic roles. 


\section{Managers'strategic roles: A reaction to top managers' sensegiving}

A first research strand concerns the top managers' efforts to shape or frame other managers' understandings of their roles, in particular during strategic change. In this perspective, top managers are seen first as engaged in sensemaking activities so as to make sense of the strategic orientations and the organizational structure supporting this strategy, and second as committing to sensegiving activities so as to convince the managers and the other organizational members to embrace their vision (cf. Gioia \& Chittippeddi, 1991). In an in-depth investigation of the effects of top management's discourse on managers' understanding of their roles in the strategy process, Mantere and Vaara (2008), and Laine and Vaara (2007) show two contrasting reactions from managers and other organizational actors. Whether promoting a participative or a hierarchical, disciplinary (non-participative) concept of the strategy process, managers generally adhere to the discourse promoted by top managers. However, a few managers do resist top manager's expectations, in particular when these are understood as an attempt from top managers to reinforce their hegemony (Laine \& Vaara, 2007) or to keep managers in a rather passive or subordinate role of execution (Mantere \& Vaara, 2008). Far from always taking on the expected role of a passive transmitter of corporate strategy, some managers even develop counter-conceptions through which they reaffirm their roles as strategic innovators (Laine \& Vaara, 2007) or promote a more collective vision of the strategic process (Mantere and Vaara, 2008). These results confirm previous research on identity regulation (Alvesson \& Willmott, 2002), which outlined that organizational members may either endorse or resist identity regulation ${ }^{3}$ attempts from the organization.

\footnotetext{
${ }^{3}$ Identity regulation refers to the organization's discourses and practices that seek to shape the worker's identity (see Alvesson \& Willmott, 2002)
} 
While this research investigates both the top management's and the other's managers sensegiving/sensemaking, a second research strand focuses on the middle managers' sensemaking process during strategic change.

\section{Managers' strategic roles: managers' sensemaking}

Contrasting with the first approach, this research underscores that the discourses and practices from top management during strategic change may be unclear or even contradictory so that managers do not only react to top managers' expectations; they have to make sense of their roles as change unfolds. Balogun and Johnson (2004) show that the top management's decision to engage in a major organizational restructuring in a UK electricity provider lacked operational content so that the managers at the head of the different divisions had to make sense of the restructuring and engage in lengthy negotiation in order to mutually define their roles in the new structure. This process took place mainly through their informal interactions and outside the control of senior managers.

Other researchers have pointed out the contradictory messages addressed to middle managers during strategic change. Lüscher and Lewis (2008) show the difficulty that production team managers have in making sense of their new roles when executive managers are asking them, for example, to "build effective teams while ensuring productivity". Confronted with what the authors call the "paradox of performing", should managers take the time "to deal with conflicts" in their team or rather "keep the team focused" on productivity (p. 232)? This ambiguity is that much stronger when the discourse (valuing risk-taking and initiative, for instance) enters into conflict with practices (that reward conformity to the plans defined by top management, see Alvesson \& Sveningsson, 2003). 
Confronted with unclear or contradictory discourses regarding their strategic roles, managers must make their own sense of what is expected of them. These processes result in different understandings ranging from the adoption of a contradictory or schizoid concept of their roles, incorporating the antagonisms of the organizational discourse (Lüscher \& Lewis, 2008), from the rejection of the strategic discourse as a whole (McCabe, 2009) or to a selective reconstruction of certain aspects and the rejection of others (see Humphreys \& Brown, 2002; Clarke, Brown, \& Hope Hailey, 2009).

Manager's strategic roles: co-constructed sensemaking through conversations involving both top and the other managers

A third, emerging research strand investigates the process underlying these different sensemaking dynamics. Activating both interpretative and social-political dynamics (Rouleau, 2005), conversations that take place during formal meetings, work sessions or informal encounters are the privileged medium through which both sensemaking and organizational structuring occur (see Crevani, Lindgren \& Packendorff, 2010; Pattriotta \& Spedale, 2009; 2011; Weick, 1993; 1990). Bechky (2006) showed how, through polite admonishing, joking and thanking, role expectations in a film project can be smoothly communicated and negotiated, allowing coordination among participants to take place.

Outlining the socio-political aspect of conversations, Westley considers that they "potentially enact formal structures of domination" (our emphasis, Westley, 1990, p. 340). Conversations are, in fact, the locus of power struggles related to differences in hierarchical status (Westley, 1990; Thomas, Sargent \& Hardy, 2011), competencies, or rhetorical skills (Samra-Fredericks, 
2005; 2003) among actors. Unless the conversation turns out to be a monologue, subordinates react to the superior's communicative practices influencing, in return, the superior's behaviors. In fact, power relationships are not shaped exclusively by the superior's behaviors but also result from "the way in which participants design their interactions, because it can have the effect of placing them in a relationship where discourse strategies of greater or lesser power are differentially available to each of them" (Hutchby, 1996, p. 482, in Schneider, 2007, p. 188). With few exceptions, this co-constructive dimension of sensemaking has received little attention until recently.

Articulating sociopolitical and interpretive dimensions, Thomas, Sargent and Hardy (2011) underscored that the enactment of hierarchical relationships relies on communicative practices whereby senior managers display authority and try to impose their views on middle managers (during a workshop held as part of a change program at a telecommunication company). In this configuration, sensemaking is fragmented as the senior managers and the middle managers stick to their views and contradict each other without searching for a common ground to build on; alternatively, senior and the middle managers may incrementally build on the others' views, even if it is in opposition to one's own. These results confirm Pattriotta and Spedale's study $(2009 ; 2011)$ which shows how what they call the "interaction order" - i. e. the relational patterns that emerge out of the flow of exchanges among actors during face-to-face interactions - affects sensemaking. Detailed analysis of the meetings held during the set-up phase of a consultancy task force in an European oil company, led the authors to outline how the participants' moves to position themselves favorably in the project (at the expense of others) and the leader's aggressive attempt to regain control over the conversation contribute to a conflicting and fragmented interaction order that is reenacted from one meeting to another. In the absence of a working consensus of the participants' roles in the task force, the participants 
cannot develop a common definition of what the project itself means, leading to further loss of meaning of participants' roles in the project.

In sum, this research strand displays how the participants' discursive behaviors during conversations enact or reenact structuring processes that may reflect (or suspend, Westley, 1990) the actors' roles in the organization and thus constitute a more or less favorable platform for joint sensemaking (as opposed to a fragmented sensemaking, Maitlis, 2005 or collapse of sensemaking, Weick, 1993).

While bringing insights into the incidence of structuring on sensemaking (or lack of), the research discussed above says little about how organizational actors facing contradictory expectations from top management make sense of their roles, or said differently, how sensemaking effects the structuring process.

Capitalizing on this research, we aim to develop a micro-processual analysis of sensemaking of the managers' strategic roles during conversations between the managers and the director as they strive to develop a strategic project for a large association within the social sector. Our intention is also to contribute to the understanding of how interpretative and socio-political dynamics articulate and combine during conversations in organizations.

\section{Research Design and Methods}

\section{Research setting}

The research took place over $2^{1 / 2}$ years in a large French association within the social sector. Created in 1946, the association is a departmental organization comprised of 160 employees. As for most associations within this sector, its financial resources (annual amount of 10 million 
Euros) come largely (90\%) from general councils and, less so (10\%) from the PJJ (Protection Judiciaire de la Jeunesse / Judicial Youth Protection), a service under the auspices of the Minister of Justice.

The association's mission is defined as the protection, reception, education, social and professional insertion for children, adolescents and young adults in difficulty, danger or delinquency. These children are received by the association at the behest of the PJJ or the social services of the ASE (Aide Sociale à l'Enfance/Child Protection Agency). The association has three centers dedicated to this mission which are located a few kilometers from one another. Each serves a different population and proposes different services:

- A social and educational center (Maison d'Enfant à Caractère Social - MECS A) that accommodates 60 children between the ages of 6 and 14 for a period of 3 to 4 years with the goal of helping them assimilate socially and academically;

- An educational and professional center (MECS B) that accommodates 65 adolescents from the ages of 14 to 21 years old with the objective of professional training and social and professional insertion;

- A state approved delinquent center for educational orientation and action (MECS C) that can house approximately 30 adolescents for a period of one year with the goal of guidance, educational help and social and professional insertion.

The association also has at its disposal the service of the MO (Milieu Ouvert - Open Milieu), a service that provides social investigation and support to families and youth in difficulty.

The structure of the association has three hierarchical levels. The main office of the association (the "Bureau"), is elected by the board of directors, which names the director. The director 
heads up the four different operational entities (MECS A, B, C and MO); each entity is managed by a center manager. The director also is responsible for supervising the central administrative department that regroups the financial and human resource services of the association. Each center is then organized into services. There are 12 service managers in all and a technical advisor who reports to the administrative department. At the request of the director, all 18 managers - including the 4 center managers, the 12 service managers, the technical advisor and the director-, actively participated in the action-research described here.

\section{Participatory action-research}

The director of the association contacted the two researchers to help the managerial team define the organization's strategy. We progressively understood that defining a strategic project for the organization was a means for the organization to meet several challenges. On the one hand, the general council was asking the associations in the social sector to be accountable regarding their financial resources and to report on the quality of the services provided. This pressure for accountability, which was regarded by the members of the association as creating competition among associations, was accompanied by new legal obligations, including new procedures to guarantee greater transparency and dialogue vis-à-vis the families and the youth. The director and the managers of the association felt that the organization should develop strategic answers that met these new demands for cost control and better quality for the services provided.

On the other hand, they were convinced that the organization was ill prepared to meet these challenges. The different centers of the association had developed independently from one other, and the managers were not in the habit of working together or with the director. They had to clarify and converge on a workable definition of their roles as director and managers in the strategic project. The board of the association, which was mainly composed of retired 
notables and industrials, while lacking competencies to understand and help the organization to develop adequate strategic answers, put increased pressure on the director so that he initiated strategic change. The objective of the action-research was to help the team develop a strategic project for the association. This supposed that the managers and the director would also agree on their respective roles in the project (see also Patriotta \& Spedale, 2009; 2011).

This research borrows its methods from participatory action-research in which the problem to resolve, and the research design, are defined with the actors in the field (Reason, 1994; Whyte, 1991). While containing numerous difficulties, this research design seems to be a pertinent research alternative for understanding actors' sensemaking (Lüscher \& Lewis, 2008), as it implies that the researchers experience, from the inside, the contradictions, ambiguity and uncertainties that organizational actors are facing.

Led by the two researchers, the study relied on full-day collective work sessions as well as smaller group sessions. These sessions took place at intervals of a few weeks, allowing the researchers to synthesize the work accomplished up until that point and to give the sub-groups time to conduct specific research (for example, to study the evolution of the legislative and regulatory context, the competition, etc.).

The research was conducted in two phases:

- During the first phase (year 1 with 6 days of collective work) a strategic diagnosis was developed. This included the following meetings:

- During the first meeting, we collected each participant's view of the main issues and challenges that the organization was facing through semi-structured, written questionnaires. Basic concepts and vocabulary of strategy (e.g. the organization's 
mission, suppliers, competitors, clients/users, resources and competencies, SWOT analysis) were introduced and illustrated.

- The second meeting was devoted to a report and discussion about the main issues and problems of the association as identified by the participants in their individual questionnaires (completed during the $1^{\text {st }}$ meeting).

- During the third and fourth meetings, a strategic diagnosis of the institutional environment and the association's competitors was achieved.

- The fifth meeting was dedicated to the identification of the association's mission, involving a debate on the profile of the youth that the organization should take and the social needs that it should meet.

- During the sixth meeting, four strategic orientations revolving around the notion of "quality service provider" were identified: 1/ the definition, communication and fulfillment of common procedures and rules, $2 /$ the adaptation of the service provided to meet the needs of the families and youth, 3/ including their latent needs, and 4/ cost control.

- The second phase (year 2 with 6 meetings) was based on the work of the sub-groups which enabled the specification of these directions and the development of concrete action plans.

The project was thus formalized and presented to the board at the end of the second year of intervention.

These meetings were generally divided in two parts: $1 /$ a report on the work done during the previous meeting and $2 /$ a collective work session on a particular aspect of the strategic diagnosis or plan. The researchers guided the collective work sessions through open-ended questions (see Extract 2 analyzed below) that encouraged participants to express (e. g. what is 
your opinion about ...?) and elaborate their views about the subject at hand (e. g. what do you mean by ...? Could you develop your idea about ...?), and check that they agree on the strategic diagnosis or the actions to implement (e.g. would you agree on this point? On that action?).

\section{Data collection}

Our analysis is built on two data sources:

- Notes taken during interviews with the director conducted by one of the researchers before the beginning of the study;

- The near complete transcription ${ }^{4}$ of the work sessions that were focused on strategic diagnosis, representing a total of more than 25 hours of tape recording.

As our intention was to focus on content (rather than the details of discursive devices used by participants as in conversational analysis) during the conversations, we transcribed the conversations by following a simplified format. Because of the high number of participants at the work sessions, we were not always able to identify each speaker. When this happened we attributed the remarks heard to "Manager X". In addition, certain passages could not be transcribed as some participants were talking at the same time, or several conversations were being held simultaneously. However, in general, and without detailing all points of view of each of the participants (certain views not necessarily being expressed in the meetings themselves) the numerous conflicts and divergent opinions expressed at the meetings leave us to believe that the transcriptions give us ample and pertinent cues with which to better understand how participants make sense during these conversations.

\footnotetext{
${ }^{4}$ The passages where one or the other researcher presents a summary of the work done in the previous meetings were not transcribed. Neither were the passages of the first meeting, during which theoretical and methodological elements were presented and discussed with the participants.
} 
Our understanding of context was also based on the numerous informal discussions held during breaks and lunches and on internal documents. The documents written by the participants in their workgroups between two meetings, the different elements of diagnosis and the directions developed during the collective sessions completed our data.

\section{Data Analysis}

We focus our analysis on the first six meetings where we, as researchers, encountered difficulties both making sense of the problems of the organization and building consensus around the identification of those problems (and so on the actions to implement) among the managers.

From the very first (individual) meeting with the director, we were struck by the contradictory manner with which he defined the problem to be resolved and the roles he gave to the managers in their strategic functions. On the one hand, he diagnosed "a breakdown of the strategic functioning" that he related to "a lack of motivation from the employees" and "a lack of commitment of the managers in the strategic function". On the other hand, when we suggested a research design aimed at helping the team to collectively define the strategy of the organization, the director objected, saying that "the strategy and the projects of the association are not to be played with", "the mission of the association is clearly defined in its statutes and cannot be debated" and that "the strategic function is handed over to the managers".

We also observed a similar alternating between a participative and a hierarchical, nonparticipative concept of strategy in the group of managers during the first phase of the strategic diagnosis (see Extract 2 below). It was our feeling that, as action-researchers, we may be 
incapable of building a consensus around the role of the managers in the strategy process as the discussions were marked by a continuous coming and going between agreement and, sometimes aggressive, contestation on both the definition of managers' role and on the strategic process itself: Who was going to do what and how?

It was this observation that gave us the metaphor of "dancing in the dark". In order to understand how participants perform this dance, we systematically researched $1 /$ the discourses of the director and the managers (in the transcripts) on the strategic roles of managers, 2 / the sequences of conversations where participants swung from one version to another.

In these sequences, we noticed that they anchored their argumentation in detailed descriptions of the organization's functioning, of its strategic positioning and environment.

In order to analyze these extracts of conversations we relied on Discourse Analysis (DA) as developed by Edwards $(1994 ; 1995 ; 2006)$ and Edwards and Potter (1992), an approach and method that focuses on the way in which people describe their own and others' experiences. Following Conversational Analysis' analytical commitments, DA considers that talk is a medium for social action, so that "the analysis of discourse becomes the analysis of what people do" (Potter, 2004: 201). Rather than explaining people's talk through reference to their underlying beliefs, values, states of mind, or implicit goals, DA describes what people are actually doing when talking, for it is through these actions that people fabricate the context of their interactions and display mutual understanding (or misunderstanding).

In this perspective, institutions (and consequently organizations), exemplified by asymmetrical relationships, prototypical descriptions, or constraints on people's actions, are envisioned as 
situated constructions that are made up, attended to, and made relevant by participants during their conversations (Potter, 2004) ${ }^{5}$. In other words, the organizational or institutional dimensions are seen as enacted in, and through, the participants' talks-in-interactions.

According to Edwards $(1994 ; 1995 ; 2006)$, one should pay particular attention to the descriptions people make of their world when talking to each other, for it is through these descriptions that they perform particular actions during their conversations i. e. suggesting a particular interpretation, rejecting an anticipated interpretation, blaming the other, accounting for their or the others' actions or interpretations etc. In particular, people often describe events or experiences as instances of generalized patterns (or as exception of these). Through these scripted descriptions (Edwards, 1994), they establish a normative base against which some events or actions can be considered as normal, adequate or usual while others will be regarded as pathological, anomalous or as requiring an account. In this analysis, the details provided by the participants cannot, as such, be classified as referring to, or deviating from, this norm: one should pay attention to the ways in which participants, during the very course of the conversation, assemble details and produce a particular interactional upshot (e. g. blaming, justifying, accounting for the event in question and for the very act of reporting). Scripts are, in fact, characterized by their variability and flexibility so that their functions cannot be identified without a careful analysis of the surrounding talks.

Following these analytical commitments, we analyze the way in which participants made sense of the managers' strategic role during the conversations through descriptions of the

\footnotetext{
${ }^{5}$ This clearly distinguishes DA from Fairclough's Critical Discourse Analysis for which social reality is made of different layers of discourse (from macro Discourse to micro, situated conversations) so that one cannot analyze a conversation without taking into account the institutional discourses (or texts) that participants draw on when talking. According to DA, institutional realities are enacted in, and through, conversations and do not pre-exist these talks.
} 
organizational functioning, and, as will be demonstrated, of the organization's strategy and environment. Our analysis focuses on the particular moments of conversations where participants swing from one version of the managers' role to another in order to understand how and why they operate such moves.

In these analyses, we considered whether we, as action-researchers could have contributed to the contradictions and oscillations observed. The detailed analysis of extracts of conversations where the director and the managers swung from one version of the managers' role to another shows that we had limited, if not no influence, on the unfolding of the oscillation observed ${ }^{6}$. These elements, together with the contradictory way in which the director defined the managers' roles at the beginning of the research process, led us to believe that, while not totally lacking in influence, the researchers actually acted more in a midwife capacity, bringing contradictions to the surface, rather than creating those contradictions.

\section{Dancing in the Dark}

We first briefly present how the director and the managers define, in contradictory and confusing terms, managers' strategic roles so that we, as researchers, also felt "in the dark". We then analyze two extracts of conversations where the director and the managers oscillate from one version of their role to another through their construction of various scripts of the organization and its environment; an oscillation that resembles a sort of dance.

\footnotetext{
${ }^{6}$ While, for instance, in Extract 1, Researcher 1 tried to interrupt the confrontation between the director and the manager, the participants went on without considering the researcher's attempt. And when, in Extract 2, the researcher invited participants to agree on a definition of the organization's target, those did not hesitate to reject the proposed definition.
} 


\section{In the Dark: setting up contradictory roles}

In broad terms, the director and the managers construct two versions of the managers' strategic roles:

- A non-participatory version where the "strategic function is handed over to the managers" and their roles mainly consist of meeting their missions as defined by the state and the board. Although agreeing with the director on this first version, the director and some center managers disagree on the director's management style. While they ask for more autonomy - a laissez-faire management style - the director defends his centralizing management style as a way to insure the financial viability of the organization.

- and a participatory version where, working together and transversally, managers may find innovative answers to the complex problems of the youth in their care.

\section{A non-participatory concept of managers' strategic role}

Sometimes the director and a few of the managers would defend a disciplinary, nonparticipatory conception of strategy (Mantere \& Vaara, 2008). During our first interviews and the first collective meetings, the director defended the idea that the strategy, as defined by the board and himself, was handed over to the managers so that their roles in the strategic process mainly consisted of implementing the strategic orientations. During the $2^{\text {nd }}$ meeting, for instance, the managers discussed "the centralization of management" considering it as one of the more important organizational problems to be resolved. The director responded to this by saying that the centers, and thus their managers, are not autonomous (see Extract 1 analyzed below); that this absence of autonomy extends to the strategic level: it is not up to the centers to define strategic directions which remain a policy prerogative, meaning the prerogative of the association's board. 
While all the managers were opposed to the "centralization of the head office", two center managers agreed with this non-participative version of their strategic roles, i.e. that their roles essentially consist of satisfying the mission that was given to their particular establishment. When the group worked on defining the global mission of the association during the $5^{\text {th }}$ meeting, they questioned the pertinence of this work for the association as a whole and, indirectly, their participation in the strategic project.

Center Manager (MO): I ask myself if this level [of the association as a whole] is relevant enough to work on [...] Working on the strategic level of the association and in its mission, I wonder if it is the best place to act, the most effective $[\ldots]$

This does not mean that they agree with the centralized management style of the director. While accepting their role of passive transmitter of the directives of the head office to the operational level, they also want more autonomy and room for maneuvering in the fulfilling of their missions; a call that led to an open conflict with the director during the second meeting (see Extract 1 analyzed below).

\section{A participatory concept of managers' strategic role}

Contrary to the previous, rather passive, concept of the managers' strategic role is a vision that is more participatory and collective. During our second interview, the director reformulated the problem he encountered as "the breakdown of strategic function", meaning a lack of involvement of the managers in the elaboration of a strategic function. He then agreed to have the managers participate in the development of the strategic project. At the end of the $5^{\text {th }}$ meeting, when the group was striving to define the mission of the organization, he even goes as far as talking about the "strategic will" of the group of managers. The director also defended the idea that managers are not simple executors of a given strategy responding to the mandates 
of the state, but that they are capable of working together, "transversally" and of innovating. When we completed the strategic diagnosis of the association during the $3^{\text {rd }}$ meeting and defined its missions as "a provider of social services" responding to the mandates of the state, the director protests:

Director Not only, not only! We are looking to develop new answers; we do not only apply existing mandates. [...]. We don't just execute solutions. Even if there are limitations, we are also innovators.

Here, the director is defending a participatory concept of strategy; a vision that is also defended and expressed by some managers through the notion of "transversal work" during the $5^{\text {th }}$ meeting. This transversal work (i.e. working "at the level of the association as a whole", "with all its centers and services") is justified by the complex problems of the young that are seen in the centers (see also Extract 2 analyzed below).

Center Manager (MO): [...]That is what interests me, working in that sphere at the level of the association as a whole, to internally work to find a solution, with all its centers and services, and modalities that could be put into place to help those [the young] that we see in MO for whom we have no ready answers.

This work is also justified by the very notion of "association" which indicates filling a void left by the state, satisfying needs that are not covered by the state through new services.

Service Manager (MECS B): I believe that there is a niche to take on in terms of the current difficulties that youth are facing; a lot of institutions are getting to the end of their rope. So, there is a spot to be filled and there we can be innovators of new projects and new types of support to be offered.

\section{Dancing: oscillating between contradictory roles}

In order to understand how participants develop such contradictory concepts of their roles and oscillate between them we analyze in detail two sequences where participants swing from one version to another. 
Extract 1. Between a non-participative and a participative concept of manager's role. During the $2^{\text {nd }}$ meeting, the researchers reported on the main problems identified by the participants through the individual questionnaires collected in the first meeting. While participants agreed with the definitions of the first problems presented, a strong conflict appeared between the director and a manager concerning the centralization of the head office (see Extract 1 below), which has been identified as a major issue for the organization by a vast majority of participants. In order to clarify its meaning, Researcher 1 asked participants to define and illustrate the notion of centralization. Without specifically asking for more participation in the strategic process, a manager then recalls an episode (see beginning of Extract 1) that he presents as exemplar of a centralized decision process; thereby indirectly calling for more autonomy. He is, however, forced to step back, and so reframes the centralization problem in terms of lack of consultation or dialogue between the center managers and the director, in effect, asking for more participation in the strategy process. At first, the director defends his centralized, nonparticipatory management style and does not accept the manager's call for more autonomy. While he does not explicitly mention the managers' strategic role in the process, he defends a decision taken without referring to either the manager or the team i.e. a non-participatory concept of the managers' strategic role. He then takes the call for dialogue as an opportunity to up the ante, that is to extend the manager's interpretation to imply that the lack of dialogue is managers' fault and that they should participate in the strategic process; changing from a nonparticipative to a participative concept of strategy.

\section{Extract 1A:}

Words in CAPITALS indicate the speech became especially loud

1 Center Manager (MO): I am going to try to give you an example of centralism that shows the state 2 of the relationships among management, the head office and the Board. I was asked to study the 3 implementation of a new service, a service in family mediation. It was first initiated by a social 
4 worker in the Open Milieu service. Here, we are onto something important, the ability to listen to a 5 need expressed by a social worker. Well, it is not only the social worker that expressed this need, but 6 it is clear we were listening. So, I began to work on this project. I started with the Director who 7 expressed, rather quickly, one of the limitations of the project based on, I believed, his overall 8 knowledge of the situation. One of the limits was that financial risks must not be taken. And I have a 9 problem in proposing a new service with instructions not to take financial risks because I know that 10 we cannot even think of creating a new service if we don't accept to take some financial risks.

11 Director: but it [this answer] must be put in the ASSOCIATIVE CONTEXT! That is possibly the 12 very reason for centralization. In fact, the association is in a precarious situation that necessitates, in 13 order to continue a certain number of services and establishments, that other financial risks are 14 avoided $[\ldots]$. But anyway that's not a limit to the project.

15 Researcher: [I would like if possible to avoid...]

16 Center Manager (MO): [Yes that is why I am saying] that it is the knowledge on the part of the 17 Head Office regarding the patrimonial and financial situation of the association and the expectation 18 of the Board. So, I understand that the limit that I was told makes sense. I am not contesting that.

19 Researcher: [I ...]

20 Director: [When you say] we can't take on a project without taking on financial risks that means 21 we cannot do any project at all. But that isn't the answer that was given.

22 Center Manager (MO): that is not the answer I was given but I do have a problem with the answer.

24 Researcher: is it financial autonomy or more the absence of autonomy for the project that appears to 25 be an example of centralization or centralism?

26 Center Manager (MO): the example of centralism in that case is that a study on the financial risk of 27 the project was not done before giving the answer that financial risk should not be taken. For me, 28 that is centralism.

Below, we note the main components of the extract, considered as a set of actions and moves performed by the participants and detail how these moves rely on scripted descriptions of the organization. 
1/ The manager narrates an episode that he presents as exemplar of the centralism of the head office (1.1). In describing this particular event, he mixes specific actions ("I was asked"; "it was first initiated", 1. 2-3; "I started with", "he expressed", 1. 6-7) and generalized aspects regarding the situation ("we are onto something important", 1. 4) and his ability to deal with it ("it is clear we were listening" 1. 6; "his overall knowledge of the situation", 1. 7-8). In describing the incident, he outlines that it has generalized implications for the organization and its protagonists (1. 1. "An example of centralism that shows the state of the relationship") so that the description has the characteristics of a script (Edwards, 1994; 1995). In presenting the incident as exemplar of some general characteristics of the organizational functioning - as opposed to something uncommon - the manager protects his description against potential refutation - of it being a rare occurrence - as well as protecting himself against accusation of bias or prejudice (Edwards, 1995, p. 325). The credibility of the manager, because he is asking for more autonomy and so has an interest in the reporting of the incident, could be in doubt. The script here is a powerful device in managing this issue of credibility of both the account and the speaker so that the call for more autonomy in decision-making appears legitimate (“And I have a problem in proposing a new service with instructions not to take financial risks because ...”, 1. 8-9).

$2 a /$ The director counters this move first by suggesting an alternative interpretation of the script (1. 11-14) He complements the manager's description and gives some information about the financial situation of the organization. In so doing, he accepts the managers' description of himself as being a centralizing director, but, at the same time, presents himself as a responsible top manager who must ensure the financial viability of the organization as a whole. Complementing the managers' description, the director outlines that his centralizing management style is legitimate. 
2b/ In the next turn, although the manager does not contest these elements, he implies that he is not happy with other aspects of the episode ("I am not contesting that" [our emphasis] 1. 18), leading the director to operate a second, more serious countermove through which he contests the manager's version (that they could not do any project, 1. 21) and suggests an alternative script (1. 21 "It is not the answer that was given"). This way, he not only denies that he is refusing autonomy to the managers but also sheds doubt on the credibility of the manager's account.

3a/ The manager is then forced to step back ("it is not the answer I was given", 1. 22) but provides new information ("a study for the financial risk of the project was not done before giving the answer that financial risk should not be taken", 1. 26-28) and so develops an alternative script where the refusal of the project is not seen as a lack of autonomy but as a lack of participation and dialogue in the decision process ("for me, that is centralism", 1. 27-28). While initially asking for more autonomy, he now argues for more participation and dialogue in the decision process (1. 26-28). This new interpretation of what centralization means may be seen as a sign of the participants" "will to power". Introduced by Luhmnan and Boje (2001, p. 164) in the analysis of discourse, will to power designates the "struggle of the individual to actively reinterpret and re-story meaning from one event to the next" that is aimed at "benefiting some over others". In our view, the manager's wish to make his point pushes him to redefine his interpretation of the episode; a script that argues for a participative concept of managers' role in the strategy process.

The new version of the managers' role is confirmed in the following exchange that took place soon afterwards. 


\section{Extract 1B:}

29 Center Manager (MO): there is a problem in the functioning of the organization. And I believe that 30 it is up to us, as much as the head office, to resolve this type of problem in order to avoid feeding 31 resentment. Because there is also a risk of feeling a bit deprived of certain prerogatives as Center 32 managers, and the risk is that this will have consequences on our direct collaborators and on our 33 services. And this is something dangerous that could be put into play and that will affect even the 34 field workers, a sort of cascade effect.

35 Director: there is also a phenomenon of reproducing the mechanism of centralization both ways. 36 Center Manager (MO): yes.

37 Director: effectively, it is the head office that, to make it simple, will try to get around the 38 management teams (i.e. of the centers). There is also an opposite effect that we try to fight against 39 that the questions asked in the centers are not addressed to management but go directly to the 40 technical services in the head office.

41 Center Manager (MO): exactly.

42 Director: and in that mechanism, I wonder if there isn't an economy in terms of the management 43 teams. "We don't manage the problem", and in the end, that is "fine with us".

44 Center Manager (MO): [maybe]

45 Researcher: [but there we....]

46 Director: [I worked] 10 YEARS LIKE THAT! Just an example, I didn't take care of the budget, I 47 didn't take care of the orders, it was done elsewhere! I could ALWAYS say I wasn't happy with that, 48 but at least I didn't have to do it! Administrative accounts, training schedules, etc.!

$3 \mathrm{~b} /$ Following the previous turn, the manager explains that centralism means lack of dialogue and information among the different hierarchical levels. He now describes the organizational functioning and its consequences in general terms ("there is a problem of functioning", 1. 29; "a sort of cascade effect" 1. 34). This scripted description is also an occasion to present himself as being both a caring ("This will have consequences on our direct collaborators", 1. 32) and responsible manager ("it is up to us, as [...] to resolve this type of problem", 1. 30). By speaking in general terms and sharing his part of responsibility for the lack of participation or dialogue that he denounces (1.31) the manager is once again careful not to appear biased or prejudiced against the director. 
4/ Surprisingly, the director not only agrees with the description of the organization as implying centralization but pushes the argument further. He complements the manager's script and reciprocates the argument ("a phenomenon of reproducing the mechanism of centralization both ways", 1. 35; "the questions asked in the centers are not addressed to management but go directly to the technical services in the head office", 1. 39-40). Also, the director not only recognizes that he is a centralizing manager but is able to reciprocate the blame when he argues that this functioning suits the managers because they don't have to manage the problem ("We don't manage the problem, and in the end, that is fine with us", 1. 43). The director's will to power is manifested here when he reinterprets the centralization issue as a generalized organizational functioning - so that the problem is not due to his own management style; a reinterpretation through which he amalgamates centralization of the head office with passivity and nonparticipation from the managers. The director illustrates his point by referring to his own experience (1. 46-48) as a center manager when he did not take care of the budget or the accounts. In considering his past behavior as manager as exemplar of such passive, nonparticipatory, irresponsible behaviours, he is able to up the ante while at the same time to protect his description from a charge of bias. Again, the description of the managers' role is anchored in a generalized description of organizational functioning.

On the whole, the analysis of the extract shows that participants 1/ change from a rather nonparticipatory to a participatory version of the managers' role; $2 /$ anchor these versions and claims in scripted descriptions of the organization from which they present themselves as both credible and responsible or knowledgeable managers (cf. Edwards, 1994; 1995; 2006). These various versions and descriptions are progressively constructed in relation to the counterversions and descriptions elaborated by the other participants during the conversations (cf. Edwards, 1995, p. 329). However, through these continuous adaptations of their script, they 
lose sight of their initial position regarding the managers' role in the strategic process and end up with a version that contradicts that which was initially defended. On the one hand, the manager's stepping back and suggesting a new interpretation contradicts his initial claim for more autonomy and, on the other, the director's contestation followed by his agreement with the manager's labelling of his management as centralizing, may be seen as the participants' will to power during the conversation.

In our view, the director and the manager's will to make their point during the very course of the conversation greatly contributes to the sensemaking of the manager's role observed. In order to counter the other's argument, they refer to facts, complement the version of the episode with new facts, or agree with the others' version and "up the ante". But far from mastering the unfolding of the conversations, these two last moves may lead them both to suggest a version of the managers' role that contradicts their initial version; as if their will to power in the conversation, and their wish to escape the responsibility of the issue at hand, release so much energy that they lose control of their argumentation.

Of course, those changes may not be a problem in themselves, if they did not happen again and again, rendering the sensemaking of managers' role unstable and equivocal during the entire diagnosis phase of the research. It also impedes the creation of a common ground for making sense of the strategic orientations to be followed by the organization (see also Patriotta and Spedale, 2009).

While dealing with the organization's mission, the sequence of the $2^{\text {nd }}$ extract ( $5^{\text {th }}$ meeting) is, in fact, similar to Extract 1 . The swinging from one version to another is not initiated by the director but by another manager and operates between a participatory and a non-participatory concept of managerial role. Interestingly, the sensemaking of managers' roles in the strategic 
process is this time related to discussion concerning the mission of the organization and its environment.

Extract 2. Between participation through transversal work and lack of participation and innovation. During the $3^{\text {rd }}$ and the $4^{\text {th }}$ meetings, the group completed a strategic diagnosis of the association. During the $5^{\text {th }}$ meeting, as we were discussing the organization's mission and main target, the issue of the managers' role in the strategy process was again put on the table. At the beginning of the meeting, participants defined the organization as a "service provider" yet progressively recognized that it was also able to innovate and propose new services to the unmet needs of the youth in question. For some managers, this "innovator" positioning implies that they would work together, transversally, so as to propose complex solutions to the complex problems they encounter; others expressed some reluctance as this positioning would also expect them to welcome "the most difficult" cases. The director takes this reluctance as an opportunity to present the managers as passive, incapable or unwilling to participate to the strategic process. The conversation had initially constructed the managers as capable of working transversally to propose collective answers to the problems of the youth, and thus as capable of participating in the strategic process; it ends up with an opposite version where they are presented as unable or unwilling to do so.

\section{Extract 2A:}

1 Service Manager (MECS A): to go back to what we were saying before [that the managers are able 2 to work transversally and to propose new solutions to the problems of the youth], I am attracted by the 3 idea of youth in the most difficult situations, because there is the feeling that it comes from 4 the complexity of difficulties. There is pathology involved, social, delinquency, etc and I am drawn to 5 the idea that we [the association] are adapted to that as we are sufficiently generalist and 6 complex. Complex problems, complex answers.

$7[\ldots]$

8 Researcher 1: does it seem to you, in particular for those who weren't in favor of [the expression of] 9 "youth in the most difficult situations", does this idea (given that the term may not be the best, but it 
10 is not destined for an ad campaign) if you say the most complex association, that may seem a little 11 impenetrable.

\section{Laughter}

13 Researcher 1: but didn't you... isn't there a consensual dimension to which the group of centers and 14 services could adhere to?

15 Manager X: but what bothers me, is the "most" term.

\section{Inaudible noise}

17 Service Manager (MECS A): the "most" [that the association brings] is the complexity of the 18 situations.

19 Manager X: but one can say [that we take on youth] in great difficulty. The "most" implies 20 [thinking in terms of] competitive positions. [I prefer] In very deep or deep difficulty. But 21 again....Again I hear Mr. Z (service Manager MECS B) say, that the UER (Unités d'Education 22 Renforcée - a new public service that is designed to take in these difficult cases) are supposed to take 23 these young in great difficulty.

24 Director (Loudly): why is the public service now innovating for youth in difficulty? They [the 25 UER] don't have seminars that last, I don't know how many days, on the definition of youth in 26 difficulty! They say placement structures must be created for this youth. It is in the texts! And they 27 are doing this and innovating because the associations ARE NOT, it must be said, capable of doing so!

28 Manager X: and yet the question of means does not surface for the UER.

29 Director [Loudly]: THE QUESTION OF MEANS...THE QUESTION OF MEANS! Have the 30 means for our association regressed?

31 Manager X: no, but in comparison to the UER...

32 Director: ...the means of the association HAVE NOT been reduced since 1946!

33 Manager X: yes, but in the UER, there is one educator per youth.

34 Director: it always comes back to the pertinence of our organizations! We often say that in 35 budgetary meetings [with the general council]. Here, we don't discuss the financial means, we 36 discuss projects and afterwards we discuss the means. What do you propose? Effectively, if there 37 isn't the [strategic] will, it will be difficult to work on these projects; the organization of it and the 38 taking over of the problem.

\section{9 [Silence]}


1/ Manager (MECS A) initially defends a collective and participatory concept of managers' role in the strategy process where, through transversal work, the manager could propose new solutions to the problems of the youth. In order to justify this, she describes in general terms the situation of the young (1. 4) and relates it to the organization's capabilities (1. 5-6) and mission - which is defined as providing complex answers to the complex problems of the youth (1. 6). Through this script, she not only defines the managers' team as capable of working transversally and innovating, but also herself as a strategist when she establishes a one-to-one correspondence between the organization's target and its capabilities.

In order to, at least temporarily, stop the oscillation observed between the different versions of the managers' roles, Researcher 1 asks the group if this definition of the organization's mission ("the most complex association", 1. 10) may federate the group (1.13-14).

2/ Managers express their reticence by laughing (1. 12). Manager X contests this expression ("what bothers me, is the term 'the most'", 1.15)

3/ and suggests a less extreme formulation ("One can say in great difficulty", 1. 19). Referring to facts, he explains that UER (Reinforced Education Centers), a specific social service of the state, are designed to take the young in great difficulty (1.23) and that they have more human and financial resources to accomplish this mission ("the question of means does not surface for the UER", 1. 28; "In the UER, there is one educator per youth", 1. 33). Through this comparison, the manager questions the first manager's scripted description of the organization as capable of taking the young in great difficulty. He does not contest the organization's capability to work transversally as such, but then reinterprets that as being a question of available means compared to those of the UER; a reinterpretation behind which one may see either an anticipative argument to obtain more financial resources or to refuse to take in the most difficult cases. 
4/ The director agrees that the UER takes the most difficult cases but he complements the description by exaggerating their capabilities compared to that of the association; the UER are innovating, they say placement structures must be created and they do it (1. 26 to 28). When manager X counters that public services have more means, the director opposes that by shouting that the financial means of the association have not been reduced since 1946 (1. 32). He also supplements his description of the UER and contrasts their high capabilities and efficient functioning with those of the associations ("They don't have seminars that last, I don't know how many days, on the definition of youth in difficulty!", 1. 24-25; "it always comes back to the pertinence of our organizations!”, 1. 34-35). He also reports on a dialogue with the general council about the budget of the association and presents it as exemplar of what the general council demands of the association. Through this script, he points out the importance of the ability to propose projects, and the lack of "strategic will" of the managers of the association ("if there isn't the [strategic] will", 1. 36-37). The director's descriptions of the UER and that of his dialogue with the general council are used to characterize the group of managers as unwilling and incapable of proposing projects and innovative solutions (and, indirectly, of not being able to work transversally).

Through their reinterpretation, the director not only constructs the group as unwilling to work transversally - which contradicts what manager A argued for at the beginning of the extractbut also rejects the responsibility for this lack; a move behind which one may again see the director's will to power.

To summarize, this section shows that the participants move from a participatory and innovating concept of the managers' strategic role to a rather passive and non-participatory one. The 
oscillation is not anchored in a scripted description of the organization's functioning, as in Extract 1, but on that of the situation of the youth and the capacity of the organization to develop adequate answers to these problems. Also, as observed in Extract 1, the different versions of the managers' role and of the organization's capabilities are progressively constructed in relation to the version elaborated by the other participant to oppose it through reference either to the terms used to describe the situation ("complex" as opposed to "the most complex") or to facts (i.e. the financial means of the UER compared to those of the organization, the dialogue with the general council). While carefully adapting or responding to one another's script, participants end up with a version of the managers' role that contradicts that which was initially defended. As in the first extract, behind these moves the participants' and in particular the director's - will to power is apparent during the very course of the conversation; that is a will to reject the responsibility of the issue at hand that goes as far as trying to make their point heard at the expense of the point itself. The oscillation is also highly related to the lack of agreement among the managers around the youth that the organization should take in (the most difficult ones or not) and to the strategic orientations to follow (that of an innovator or of a service provider).

Extract 2B followed directly after Extract 2A, and shows how an external reference permits the managers and the director to reconcile themselves around a consensual dimension of their roles as strategists - at least temporarily. It also provides some cues about the reason of the dance observed.

\section{Extract 2B:}

40 Service Manager (MECS B): maybe that is why we are reticent, because there may be judgments 41 that are not explicit and the fear that, in terms of the association's policy, is that it will be 42 translated as "take in the most disturbed young as long as that is your vocation", maybe the fear at 43 the strategic level, that the board doesn't take into account, is that it will necessitate a total 44 reorganization of 
intake methods. It may not be said but there are issues like this. And if there are, it 45 must be said. Because if there are fears about this, it is in the strategic sphere and we must find 46 the method to communicate a certain amount of clear and coherent messages to the board.

47 Director: I believe that, yes, there is something like that, it is what I tried to say this morning...the 48 discomfort in talking about these very disturbed youth. I believe that brings us back to the fear of 49 being in difficulty in general and that goes along a little bit with what you just said. If we enter into 50 this particular niche, will it end up being us, ourselves, who will be in great difficulty because we 51 just don't have the proper means, etc.

In this second part of the extract, the MECS B service manager recognizes their reservations ("that is why we are reticent", 1. 40) and, indirectly, their lack of strategic will ("the fear, that in terms of the association's policy", 1. 41; "maybe the fear at the strategic level", 1. 42) but on the one hand, relates it to the "most disturbed youth" that these innovations would target ( 1 . 42), and, on the other, to the risk that the board will not take into account the vast reorganization that this would imply (1. 43-44). Although speculative, the description of the managers' fear permits the manager to position himself both as knowledgeable and courageous ("if there are, it must be said", 1. 44; "we must find the method to communicate ...", 1. 45-46). This script is different from the previous ones in that it does not put the managers in opposition to the director but contrasts the strategic group (which seems to now include both the managers and the director) with the board, thereby affirming the existence of a competent and proactive strategic group capable of taking and communicating a firm position vis-à-vis the board (1. 46-47).

The director, as a member of the strategic group (and who sometimes feels his position threatened by the board), agrees (1. 47). Here the reference to the board creates, by contrast, the strategic group which includes both the managers and the director; an inclusion that for the moment overcomes direct confrontation between them as well as the dance previously observed. One should not conclude that this conversation puts an end to the oscillation. In referring back to the morning's discussion about "these very disturbed youth" (1. 48), the 
director also comes back to their exchange about the lack of means (1. 49-51). While agreeing with the manager at that point, he also wants to have the last word; in doing so his agreement appears quite ambiguous.

From here, one may hypothesize that the discussions around the organization's capability and functioning constructs a strategic team that is defined in terms of an opposition between the managers and the director, thereby exacerbating the participants' will to power during collective work. Yet, alternatively, a discussion about the relationship between the group and the board seems to move participants' attention towards a more inclusive and contextualized view of the team that temporarily suspends the opposition between the director and the managers. On the whole, how participants make sense of the issue at hand influences their understanding of the relationship between the managers and the director, in oppositional terms or not; an understanding that, in turn, activates or suspends participants' will to power and political struggles during the meeting.

\section{Discussion}

This research contributes to the understanding of how managers make sense of their strategic roles during strategic conversations when confronted with contradictory expectations from top management. This contribution is threefold.

First, complementing prior research on role sensemaking and on Edwards' (1994; 1995) work on scripts, our results demonstrate that sensemaking activities of managerial roles are anchored in scripted descriptions of the organization and its environment. Role construction is an intermediary "within the relational processes of meaning construction" (Simpson \& Carroll, 
2008, p. 33), so that altering how the relation is understood and the terms of the relation can change the meaning of the role. While recent research have explored the discursive tactics and practices used by participants during conversations to convince the audience (i. e. Thomas et al., 2011; Samra-Fredericks, 2003; Pattriotta \& Spedale, 2009; 2011), much less is known about the actual content of these conversations and its incidence on sensemaking. Our research confirms that participants make sense of their roles in relation to themselves or others, as Simpson and Caroll's definition (2008) suggest. In particular, while the group changes from one version of the managers' role to another during the five first meetings, it arrives at some consensus when the director and the managers both refer to the board. This external reference creates the "strategic group", thereby temporarily putting an end to the confrontation between the managers and the director. This confirms that the relative positioning of the actors vis-à-vis the other, and thus the interpretive frame through which they "see" this other, are crucial elements driving the sensemaking process (Weick et al., 2005).

Complementing Carroll and Simpson's view, our research also shows that the sensemaking process of a managerial role is highly related to that of the organization and its environment. When making sense of the managers' role in the strategy process, participants do not exclusively refer to the director or to the board, but always replace the managers' role in a generalized description of the organization and/or of its environment. These generalized descriptions often refer to, or carry within themselves, conflicting demands presented as coming from the general council (being accountable for their financial resources and improving the service quality) or from the social sector (meeting new, unmet social needs as in the past and meeting the state's demands only). Further research is needed here on how organizational members enact or ignore potential contradictions emanating from their environment and its history. 
Following Edwards (1994, p. 325), these scripted descriptions may be interpreted as a way to depoliticize the issue of role in the organization. They help participants establish their account as unbiased and build a picture of themselves as neutral reporters of facts as opposed to that of a self-serving or self-interested person. Referring back to events, incidents and episodes, the question of managerial roles becomes a rational and technical problem (as opposed to an issue of power and personal interest), so that the use of scripted descriptions permits managers to appear unbiased, but also competent, knowledgeable, responsible and apt to think strategically. Scripts are constructed as a platform of legitimacy from which to claim a particular version of managers' strategic role. Complementing Edwards (1994; 1995), our results show that participants in an organizational context construct not only scripted descriptions of their particular personal experiences or events, but also of the organization and its environment.

Further research is needed on the content of the conversation as it is believed that what is said is complementary to how it is said in sensemaking processes (the discursive devices and tactics used, see Edwards, $1994 ; 1995)$ and that it greatly contributes to the power struggle during the conversation. Longitudinal studies on the interactions between managers and top managers are also needed in order to get a deeper understanding of how contradictions evolve over time and of their consequences on the managers' and staff's behaviors and engagement within the organization.

Second, our research shows how the managers and the director both contribute to the fabric of contradictory versions of the managerial roles. Previous research on strategy discourses (e.g. Laine \& Vaara, 2007; Mantere \& Vaara, 2008) has underscored that managers, confronted with contradictory expectations from top managers reject, or adopt, top managers' versions, or 
develop specific versions that selectively incorporate some elements and reject others. Contrasting with these results, our analysis of the conversation show that managers are not just reacting to the sensegiving efforts of top management (e.g. Gioia \& Chittipeddi, 1991), but that they actively participate in the sensemaking of their roles and to the contradictions observed in their conversations with the director. These elements also demonstrated that differences in sensemaking may not only be due to differences of hierarchical positions (Mantere \& Vaara, 2008), functions (Laine \& Vaara, 2007; Suominen \& Mantere, 2010), or audiences (Vaara, 2003), but that the same actors may hold different views during a conversation as the result of their confrontation with other participants.

These results, along with others (see Balogun \& Johnson, 2004; 2005) invite us to distance ourselves from the portrayal of strategic change as made up of successive phases of sensemaking and sensegiving, mainly dominated or directed by top managers. It also encourages us to investigate sensemaking through naturally occurring talk rather than interviews or documentary data (see also Silverman, 2006).

This co-constructive view of the sensemaking of managers' strategic role also complements extant literature on identity work (Alvesson \& Willmott, 2003; Watson, 2008). While defining self-identity in constructive and "relational" terms, this research views identity work as the individual's work on social identities that are publicly available through discourses (Watson, 2008) or promoted by the organization (Alvesson \& Sveningsson, 2003; Alvesson \& Willmott, 2003); so that identity work implies a relationship that is asymmetrical and ideational. Though not contesting the relevance of such processes in a world where the individual is submitted to multiple and often contradictory discourses on how one should be or behave (Watson, 2008), our results differ from identity work research by showing $1 /$ how roles - as intermediaries 
between self-identity and others - are constructed through conversations between organizational members (through (small d) discourses as opposed to (Big D) Discourses, Alvesson \& Kärreman, 2000; 2011) and 2/ how their various discursive moves may contribute to the contradicted versions of their roles (vs. rely on available Discourses only).

Finally, going into the details of a strategic conversation, the research outlines the discursive actions through which participants fabricate conflicting versions of the managerial role and oscillate between them. Although the specific subject matter and actors change, both extracts display a similar organization that can be summarized as follows:

1. Manager A describes one's role as strategic manager and/or the director's role through a scripted description of the organization (version 1);

2. Manager B, or the director, counters manager A's script by referring to facts (not version 1);

3. Manager A steps back. An alternative version of the manager's role and related script is suggested through the addition of other facts; the new version contradicts the one initially suggested (not version 1 becomes version 2);

4. The director agrees with this new version of the manager's role but pushes the argument further which leads him to contradicts himself (version $2++i$ is version 1 ).

Although needing replication, these results shed light on the politics of interpretation. In our view, the participant's will to power during the very course of the conversation contributed to the discursive fabric of contradictory versions of managerial roles, on the oscillation between those versions and the resulting dance observed. Following the dance metaphor, it seems that participants' will to have the last word during the conversation is sometimes so strong that they lose control over their argumentation; that will to power sometimes releases so much energy 
that their argumentation just slides away from them. While power is usually associated with control over the others, as well as, over the course of the conversation (Samra-Fredericks, 2003) and that of manipulation (Rouleau \& Balogun, 2011, p. 976), our research confirms Haworth (2006)'s analysis that taking control of the conversation might be done to one's own detriment. "Power and control can always be challenged by the use of discursive strategies, regardless of the subject matter, the status of participants, or any other factor. However [...], they might not be wise in this context, and can in fact lead to weakening the challenger's position in the wider sense [...] Thus it is just as important to know when to relinquish power and control in this context as it is to maintain it" (Haworth, 2006, p. 755). This result echoes Pattriotta and Spedale (2009)'s analysis of conversations in a consultancy task force where power struggles between consultants over their roles in the project led to entrenched warfare and loss of sensemaking. However, further research is needed to better understand how and why conversations sometimes lead to a positional warfare (as observed in Pattriotta \& Spedale, 2009) or to the dance in the dark observed in our research.

In summary, our research shows that the fabric of contradicted concepts of managers' strategic roles relies on situated constructions of scripted descriptions of the organization and its environment; a sensemaking process that is driven by the participants' will to power during the very course of a conversation and that is far from being mastered by participants. In our view, this invites us to explore the uncontrolled dimensions of power and sensemaking in organizational life, a dimension that is today underinvestigated in management and strategy research, even in its strategy-as-practice approach.

Although contributing to our understanding of sensemaking during conversations, our research has limitations. 
First, the extracts of conversation reported in this research have been translated from French to English. Some important nuances may have been lost in the reporting of the events and other meanings added (cf. Mantere \& Vaara, 2008). In order to limit these possible distortions in interpretation, the research and the analysis was conducted entirely in French and only then translated in English.

Second, it was not possible to know the way in which the different strategic roles constructed by the managers during the conversations were actually played out in their centers (cf. Lüscher \& Lewis, 2008). Even when we were able to pick up on the ambivalence of certain actors in the course of the group conversations, we did not seek to appreciate the degree to which they continued to individually defend contradictory conceptions of their role (cf. Vaara, 2003). However, the use of naturally occurring talk (as opposed to interview data) is a step towards a deeper understanding of how managers make sense of their roles as they interact with one another in the organization. In our view, further research is needed to appreciate how the roles constructed in interviews, strategic conversations (cf. this research) and during day-to-day interactions (cf. Rouleau, 2005; Rouleau \& Balogun, 2011) will continue to converge or differ.

Finally, for lack of space, the interpretation suggested did not analyze in-depth our own contribution to the dance. As participatory action-research members, we sought to understand the different viewpoints expressed by participants. Through questioning, looking for clarification and further justifications, we may have exacerbated the contradictions expressed by participants. They may also have "instrumentalized" us - using us to insure that their points were heard by the director. At the same time, as we were actively looking for some common ground among participants (see Extract 2) on which to develop the strategic project, we may 
have undermined some differences between interpretations. While it is clear that we did contribute to the sensemaking process, the size of the group (18 managers), on the one hand, and our permanent feeling of confusion during the first meetings, on the other, incline us to believe that we were more interpreters (amplifying or reducing) than choreographers of the dance described here.

\section{References}

Alvesson, M., Ashcraft, K. L., \& Thomas, R. (2008). Identity matters: reflections on the construction of identity scholarship in organization studies. Organization, 15(1), 5-28.

Alvesson, M. \& Kärreman, D. (2000). Varieties of discourse: On the study of organizations through discourse analysis. Human Relations, 53(9), 1125-1149.

Alvesson, M. \& Kärreman, D. (2011). Decoloniazing discourse: Critical reflections on organizational discourse analysis. Human Relations, 64(9), 1121-1146.

Alvesson, M., \& Sveningsson, S. (2003). Good visions, bad micro-management and ugly ambiguity: contradictions of (non-)leadership in a knowledge-intensive organization. Organization Studies, 24(4), 961-988.

Alvesson, M., \& Willmott, H. (2002). Identity regulation as organizational control: Producing the appropriate individual. Journal of Management Studies, 39(5), 619-644.

Balogun, J., \& Johnson, G. (2004). Organizational restructuring and middle manager sensemaking. Academy of Management Journal, 47(4), 523-549.

Balogun, J., \& Johnson, G. (2005). From intended strategies to unintended outcomes: the impact of change recipient sensemaking. Organization Studies, 26, 1573-1601.

Bechky, B. A. (2006). Gaffers, goffers, and grips: Role-based coordination in temporary organizations. Organization Science, 17(1), 3-21. 
Bechky, B. A. (2011). Making organizational theory work: Institutions, occupations, and negotiated orders, Organization Science, 22(5), pp. 1157-1163.

Clarke, C., Brown, A., \& Hope Hailey, V. (2009). Working identities? Antagonistic identities resources and managerial identity. Human Relations, 62(3), 323-352.

Crevani, L., Lindgren, M. \& Packendorff, J. (2010). Leadership, not leaders: On the study of leadership as practices and interactions. Scandinavian Journal of Management, 26, 77-86.

Edwards, D. (1994). Script formulations: An analysis of event descriptions in conversation. Journal of Language and Social psychology, 13(3): 211-247.

Edwards, D. (1995). Two to Tango: Script formulations, dispositions and rhetorical symmetry in relationship troubles talk. Research on language and social interaction, 28(4): 319-350.

Edwards, D. (2006). Facts, norms and dispositions: practical uses of the modal verb would in police interrogations. Discourse Studies, 8(4): 475-501.

Edwards, D. \& Potter, J. (1992). Discursive Psychology. London: Sage Publications.

Ford, J. (1999). Organizational change as shifting conversations. Journal of Organizational Change Management, 12 (6), 480-500.

Foucault, M. (1982). The Subject and Power. In Michel Foucault: Beyond Structuralism and Hermeneutics, edited by H. Dreyfus and P. Rabinow, pp. 208-226. 2nd ed. Chicago: The University of Chicago Press. http://foucault.info/documents/foucault.power.en.html

Gioia, D. A., \& Chittipeddi, K. (1991). Sensemaking and sensegiving in strategic change initiation. Administrative Science Quartely. 12, 433-448.

Haworth, K. (2006). The dynamics of power and resistance in police interview discourse. Discourse \& Society, 17(6): 739-759.

Heritage, J. (1987). Ethnomethodology. In N. K. Denzin and J. H. Turner (eds), Social Theory Today, pp. 224-272. Stanford, CA: Stanford University Press. 
Humphreys, M., \& Brown, A. (2002). Narratives of organizational identity and identification: a case study of hegemony and resistance. Organization Studies, 23(3), 421-447.

Hutchby, I. (1996). Power in discourse: The case of arguments on a British talk radio Show. Discourse and Society, 7, 481-497.

Laine, P.-M., \& Vaara, E. (2007). Struggling over subjectivity: A discursive analysis of strategic development in an engineering group. Human Relations, 60(1), 29-58.

Luhman, J. T., \& Boje, D. M. (2001). What is complexity science? A possible answer from narrative research. Emergence, 3(1), 158-168.

Lüscher, L. S., \& Lewis, M. W. (2008). Organizational change and managerial sensemaking: working through paradox. Academy of Management Journal, 51(2), 221-240.

Maitlis, S. (2005). The social processes of organizational sensemaking. The Academy of Management Journal, 48(1), 21-49.

Maitlis, S. and Sonenshein, S. (2010). Sensemaking in crisis and change: Inspiration and insights from Weick (1988), Journal of Management Studies, 47, 551-80.

Mantere, S. (2008). Role expectations and middle managers strategic agency. Journal of Management Studies, 45(2), 294-316.

Mantere, S. (2005). Strategic practices as enablers and disablers of championing activity. Strategic Organization, 3(2), 157-184.

Mantere, S., \& Vaara, E. (2008). On the problem of participation in strategy: a critical discursive perspective. Organization Science, 19(2), 341-358.

McCabe, D. (2009). Strategy-as-Power: Ambiguity, contradiction and the exercice of power in a UK building society. Organization, 17(2), 151-115.

Patriotta, G., \& Spedale, S. (2011). Micro-interaction dynamics in group decision making: Face games, interaction order and boundary work. Scandinavian Journal of Management, 27, 362374. 
Patriotta, G., \& Spedale, S. (2009). Making sense through face: identity and social interaction in a consultancy task force. Organization Studies, 30(11), 1227-1248.

Potter, J. (2004). Discourse analysis as a way of analysing naturally occurring talk In D. Silverman (ed.), Qualitative research: Theory, Method and Practice, $2^{\text {nd }}$ ed. London: Sage Publications, pp. 200-221.

Reason, P. (1994). Three approaches to participative inquiry. In N. Denzin \& Y. Lincoln, (Eds), Handbook of qualitative research (pp. 324-339). London: Sage.

Regnér, P. (2003). Strategy creation in practice: Adaptive and creative learning dynamics. Journal of Management Studies, 40(1): 57-82.

Rouleau, L. (2005). Micro-practices of strategic sensemaking and sensegiving: how middle managers interpret and sell change every day. Journal of Management Studies, 42(7), 14131441.

Rouleau L., \& Balogun J. (2011). Middle Managers, Strategic Sensemaking, and Discursive Competence. Journal of Management Studies, 48(5), 953-983

Samra-Fredericks, D. (2003). Strategizing as lived experience and strategists' everyday efforts to shape strategic directions. Journal of Management Studies, 40(1), 141-174.

Samra-Fredericks, D. (2005). Strategic practices, 'discourse' and the everyday interactional constitution of 'power effects'. Organization, 12(6), 803-841.

Simpson, B., \& Carroll, B. (2008). Reviewing 'role' in processes of identity construction. Organization, 15(1), 29-50.

Silverman, D. (2006). Interpreting qualitative data, 3rd ed. London: Sage Publications.

Schneider, B. (2007). 'Power as interactional accomplishment: An ethnomethodological perspective on the regulation of communicative practice in organizations', in M. Zachry and JYC. Thralls (eds.), Communicative practices in workplaces and the professions: Cultural 
perspectives on the regulation of discourse and organizations, 181-202. Amityville, NY: Baywood Publishing.

Suominen, K., \& Mantere, S. (2010). Consuming strategy: the art and practice of managers' everyday strategy usage. Advances in Strategic Management, 27, 211-245.

Thomas R., Sargent L. D., Hardy C. (2011). Managing Organizational Change: Negotiating Meaning and Power-Resistance Relations. Organization Science, 22(2), 22-41.

Vaara, E. (2003). Post-acquisition integration as sensemaking: glimpses of ambiguity, confusion, hypocrisy, and politicization. Journal of Management Studies, 40(1), 859-894.

Vaara, E. (2010). Taking the linguistic turn seriously: strategy as a multifaceted and interdiscursive phenomenon. Advances in Strategic Management, 27, 29-50.

Watson, T. J. (2008). Managing identity: Identity work, personal predicaments and structural circumstances, Organization, 15(1): 121-143.

Weick, K. (1990). The vulnerable system: an analysis of the Tenerife Air disaster. Journal of Management, 16(3), 571-593.

Weick, K. (1993). The collapse of sensemaking in organizations: the Mann Gulch disaster. Administrative Science Quarterly, 38, 628-652.

Weick, K. (1995). Sensemaking in organizations. Thousand Oakes: Sage.

Weick, K., Sutcliffe, K., \& Obstfeld, D. (2005). Organizing and the process of sensemaking. Organization Science, 16(4), 409-421.

Westley, F. (1990). Middle managers and strategy: microdynamics of inclusion. Strategic Management Journal, 11, 337-351.

Whyte, W. F. (1991). Participatory action research. London: Sage.

Ybema, S., Keenoy, T., Oswick, C., Bevereungen, A., Ellis, N., \& Sabelis, I. (2009). Articulating identities. Human Relations, 62(3), 299-322. 